\title{
A REPRODUÇÃO DA METRÓPOLE AMAZÔNICA: MANAUS E AS NOVAS DETERMINAÇÕES URBANAS
}

\author{
Eduardo Henrique Freitas Braga \\ Mestranda do Programa de Pós-graduação em Geografia - UFAM \\ Universidade Federal do Amazonas \\ eduardohfreitasbraga@gmail.com \\ José Aldemir de Oliveira \\ Professor Doutor do Programa de Pós-graduação em Geografia - UFAM \\ Universidade Federal do Amazonas \\ jaldemir@ufam.edu.br \\ César Ricardo Simoni Santos \\ Professor Doutor do Departamento de Geografia da USP e do Programa de Pós-graduação em \\ Geografia Humana da Universidade de São Paulo \\ cesarsimoni@usp.br

\begin{abstract}
RESUMO: A pesquisa tem como ponto de partida a rodovia estadual AM-070 para pensar o momento de reprodução do espaço urbano-metropolitano da capital amazonense e como tal processo ocorre em suas contradições (pelo setor imobiliário), apontando para a homogeneização do espaço que tem como forma contemporânea o urbano. Nesse sentido, o urbano como negócio media o sentido da reprodução e permite pensar sobre o Desenvolvimento Espacial Desigual que encontra neste urbano, sua possibilidade de realização.
\end{abstract}

Palavras-chave: Espaço urbano-metropolitano, AM-070, Mercado imobiliário.

\section{INTRODUÇÃO}

A pesquisa pretendida aqui busca alcançar uma compreensão acerca da reprodução do espaço urbano-metropolitano de Manaus a partir de suas novas determinações: o sentido da expansão da metrópole manauara apresenta uma nova condição no seio das transformações do urbano na contemporaneidade, no qual a rodovia estadual AM070 se apresenta enquanto um fragmento do espaço metropolitano da capital amazonense, dando sentido à reprodução do capital pela metrópole e sua expansão na ponta desse processo. Tomando como lugar de análise a rodovia, estabelece-se um fragmento potencialmente revelador das dinâmicas emergentes no processo de reprodução da metrópole manauara. A urbanização da sociedade se dialetiza então com a urbanização do território, trazendo, o primeiro termo, outros conteúdos na constituição de um pensamento sobre o urbano em um lugar da Amazônia, a partir da Geografia. A centralização da reprodução do espaço aparece assim atravessada pela atividade imobiliária e pelo emergir de novas dinâmicas socioespaciais no bojo deste processo, e as novas determinações do lugar apontam um novo direcionamento na expansão do tecido urbano (antes no interior da própria metrópole), agora extrapolando seus limites administrativos, alavancadas pela especulação imobiliária (e suas estratégias de reprodução) e num contexto mais amplo, pela redefinição de usos e sentidos da acumulação que encontram no espaço (e mais precisamente no espaço urbano-metropolitano da cidade) seu fundamento - a valorização. A partir 
A REPRODUÇÃO DA METRÓPOLE AMAZÔNICA: MANAUS E AS NOVAS DETERMINAÇÕES URBANAS

disso, um pensamento acerca da produção de um espaço homogêneo, tendo como elemento definidor o urbano como negócio, se exige como necessário ao se desvendar, nos conteúdos do fragmento em análise, o horizonte de uma sociedade urbana em conformação, iluminando assim, o que denominamos Desenvolvimento Espacial Desigual. O que aparece como mote da pesquisa, portanto, se localiza no processo de reprodução do espaço a partir da metrópole, trazendo o setor imobiliário como elemento empírico, e a partir dele, o urbano em sua contemporaneidade.

\section{MATERIAIS E MÉTODOS}

Parte-se do método progressivo-regressivo de Henri Lefebvre, de entender, a partir do passado, o presente em constituição e os caminhos que indiquem o horizonte do processo, ou seja, uma "démarche regressiva (indo do presente para o passado para iluminar o passado pelo que ele se tornou e o que aconteceu) e depois progressiva (retornando ao presente a partir de suas múltiplas e complexas condições, para 'analisar', não sem visar uma 'explicação' dificilmente exaustiva)" (LEFEBVRE, 1986, p. 47). A transdução também se põe como um movimento importante na realização da pesquisa, principalmente nos capítulos posteriores, construindo "um objeto teórico, um objeto possível, e isto a partir de informações que incidem sobre a realidade"

Quanto aos procedimentos metodológico, serão realizados levantamentos de dados secundários referentes à população (IBGE, DATASUS) e de dados primários e secundários referentes a dinâmica imobiliária da cidade de Manaus e do estado do Amazonas de fontes como a Associação das Empresas do Mercado Imobiliário no Estado do Amazonas (Ademi-AM) e o Sindicato da Indústria da Construção Civil do Amazonas (Sinduscon), além dos sites das incorporadoras e construtoras atuantes no recorte.

\section{REVISÃO DE LITERATURA}

A centralidade que o espaço como categoria de análise assume põe a cidade e o urbano em posição fundamental na compreensão das transformações socioespaciais emergentes. Nesse sentido, alguns momentos da obra de Henri Lefebvre em obras como A Revolução Urbana; O Direito à Cidade; La Producción del Espacio e Espaço e Política se fazem presentes no decorrer da pesquisa, a partir da perspectiva teórico metodológica adotada. Tal acepção se propõe em compreender assim o movimento da sociedade em sua projeção espacial - sendo o espaço meio, condição e produto dessa relação ${ }^{1}$

Inicialmente, Bertha Becker (1985) se destaca ao apontar o fenômeno urbano a partir da expansão territorial da fronteira, sinalizando ali, o papel central das cidades na organização e no controle do território. Relativos aos fenômenos urbanos na Amazônia e na cidade de Manaus e seu espaço metropolitano, alguns autores utilizados serão Trindade Jr (2000; 2015), quanto ao processo de metropolização e

${ }^{1}$ CARLOS, Ana Fani Alessandri. A Condição Espacial. São Paulo: Contexto, 2011.

REVISTA GEONORTE, V.9, N.33, p.203-206, 2018.

DOI: 10.21170/geonorte.2018.V.9.N.33.203.206

(ISSN 2237 - 1419) 
A REPRODUÇÃO DA METRÓPOLE AMAZÔNICA: MANAUS E AS NOVAS DETERMINAÇÕES URBANAS

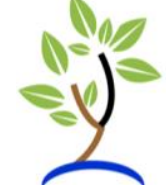

urbanização difusa na Amazônia; Oliveira (2000; 2008), ao tratar das cidades amazônicas e de Manaus e as transformações do seu espaço urbano; João Pinheiro Salazar e Márcio Souza, a respeito da Manaus em sua época industrial e Isaque Sousa $^{2}$ e Marcos Lima ${ }^{3}$, tratando do processo de metropolização a partir da Região metropolitana de Manaus (RMM).

As leituras de Carlos, em Espaço-Tempo da Vida Cotidiana na Metrópole, Simoni Santos (2006; 2011), Volochko (2015) e Lencioni (2014) orientam a discussão acerca dessa fase do setor imobiliário, suas características e estratégias reprodutivas.

Por fim, expostos esses pontos com as discussões do primeiro capítulo já tendo sido realizadas, o urbano como elemento esclarecedor nos permite culminar no terceiro capítulo da pesquisa acerca de um desenvolvimento espacial desigual (DED). A partir de leituras mais clássicas pretende-se construir um pensamento acerca do DED e entender, como em outros tempos e outros espaços, foram pensadas essas desigualdades do processo de produção. Assim, Trotsky com sua Lei do Desenvolvimento Desigual e Combinado $^{4}$, Lenin com sua reflexão sobre o Imperialismo ${ }^{5}$ e Antonio Gramsci ${ }^{6}$ com sua Questão Meridional permitirão enriquecer e atualizar o debate sobre o desenvolvimento espacial, compreendo o processo a partir da metrópole manauara e seu espaço metropolitano em constituição.

\section{RESULTADOS PARCIAIS}

O que se coloca como questão central até o momento, no processo de realização da pesquisa, se sustenta na produção do espaço urbano manauara a partir da industrialização pelo qual passou a cidade e seus reflexos na conformação territorial da metrópole. A partir disso, a produção da habitação pelo estado (os conjuntos habitacionais) e a consolidação das periferias suburbanas como resultado desse processo no contexto intrametropolitano revela o anterior papel do estado, hoje muito mais propiciador de uma atuação privada no setor imobiliário.

\section{REFERÊNCIAS}

BECKER, B. Fronteira e urbanização repensadas. Revista Brasileira de Geografia, 47 (3/4), 1985.

\footnotetext{
${ }^{2}$ SOUSA, Isaque dos Santos. A Ponte Rio Negro e a reestruturação do espaço na Região Metropolitana de Manaus: um olhar a partir de Iranduba e Manacapuru. Manaus: Editora Reggo/UEA Edições, 2015. ${ }^{3}$ LIMA, Marcos Castro de. Quando o amanhã vem ontem: a institucionalização da Região Metropolitana de Manaus e a indução ao processo de metropolização do espaço na Amazônia Ocidental. Tese de doutorado. São Paulo: USP, 2014.

${ }^{4}$ TROTSKY, León. História da revolução russa. 2ª edição. Rio de Janeiro: Paz e Terra, 1977.

${ }^{5}$ LÊNIN, V. I. Imperialismo, fase superior do capitalismo. São Paulo: Editora Centauro, 2003.

${ }^{6}$ GRAMSCI, A. Alguns temas da questão meridional. In: A questão meridional. Rio de Janeiro, Paz e Terra, 1987.
}

REVISTA GEONORTE, V.9, N.33, p.203-206, 2018.

DOI: 10.21170/geonorte.2018.V.9.N.33.203.206

(ISSN 2237 - 1419) 
LEFEBVRE, $\mathrm{H}$. Le retour de la dialectique: douze mots clefs pour le monde moderne. Paris: Messidor/Éditions Sociales, 1986.

LENCIONI, S. Reestruturação imobiliária. Uma análise dos processos de concentração e centralização do capital no setor imobiliário. Eure, vol. 40, n. 120, 2014.

OLIVEIRA, J. A. Cidades na Selva. Manaus: Valer, 2000.

OLIVEIRA, J. A. Amazônias: sociedades diversas espacialidades múltiplas. Hiléia Revista de Direito Ambiental da Amazônia, Manaus, v. 2, p. 109-114, 2006.

OLIVEIRA, J. A.; SCHOR, T. Manaus: transformações e permanências, do forte a metrópole regional. In: CASTRO, E. (Org.). Cidades na Floresta. São Paulo: Annablume, 2008. 59-98

SIMONI SANTOS, C. R. Dos negócios na cidade à cidade como negócio: uma nova sorte de acumulação primitiva do espaço. Cidades, v. 3, n. 5, 2006, p. 101-122.

SIMONI SANTOS, C. R. A Gentrificação como Atualização das Estratégias Imobiliárias: os novos dispositivos da acumulação. In: XIV ENANPUR: Quem planeja o território? Atores, arenas e estratégias. 2011, Rio de Janeiro. XIV Encontro Nacional da ANPUR, 2011. v. 1. p. 1-21.

TRINDADE JR,, S. C. A natureza da urbanização da Amazônia e sua expressão metropolitana. Geografares, Vitória, v. 1, nํ1, jun. 2000.

TRINDADE JR,, S. C.. Das "cidades na floresta" às "cidades da floresta": espaço, ambiente e urbanodiversidade na Amazônia brasileira. Papers do NAEA (UFPA), v. 321, p. 1-22, 2013.

TRINDADE JR, S. C.. Pensando a modernização do território e a urbanização difusa na Amazônia. Mercator (Fortaleza. Online), v. 14, p. 93-106, 2015.

VOLOCHKO, D.. A moradia como negócio e a valorização do espaço urbano metropolitano. IN: CARLOS, A. F. A; VOLOCHKO, D; ALVAREZ, I. P. (orgs.). A Cidade como Negócio. São Paulo: Editora Contexto, 2015.

Recebido em 13/03/2018

Aceito em 30/05/2018 